\title{
Las barricadas de Alberto Pérez. Fuerzas de combate en el arte y la política
}

The barricades of Alberto Pérez. Forces of combat in the arts and politics

\author{
Soledad García Saavedra*
}

\begin{abstract}
Resumen:
La apropiación de la barricada callejera constituye el punto de partida de la transformación artística y social del artista e historiador del arte, Alberto Pérez, quien movilizó una conciencia radical en el clima de enfrentamientos populares y revolucionarios de la década de 1960. Este ensayo reconstruye el espesor de sus pensamientos y prácticas a partir de tres momentos en que los usos de la barricada cobraron un carácter distinto según las luchas artísticas, universitarias y militares.
\end{abstract}

Palabras clave: Alberto Pérez, arte, barricadas, revolución

\begin{abstract}
:
The appropiation of street barricades encompass the standpoint of the artistic and social transformation of the artist and art historian, Alberto Pérez, who mobilized a radical conciousness in the climate of popular and revolutionary turmoil of the $60 \mathrm{~s}$. This essay reconstructs the thickness of his thoughts and practises through three moments in which the barricades' uses took on differents tempers according to artistic, university and military struggles.
\end{abstract}

Keywords: Alberto Perez, art, barricades, revolution

La barricada se asocia al mítico Mayo del 68 y en Chile, al reventón callejero de 1957. A pesar de sus ditintas temporalidades y contextos, la explosión de los enfrentamientos, la apropiación de la calle, y el frenesí violento de esas acciones, fueron episodios comunes en ambas latitudes. Asimismo, sus convicciones: destruir las vías para movilizar un cambio. A diferencia de la construcción de las barricadas de las revoluciones populares y proletarias del siglo XIX en Europa, éstas no tenían la finalidad de convertir al pueblo en carne de cañón o ser un escudo militar, más bien consistían en marcar y cubrir provisionalmente un territorio, una trinchera donde un nuevo bando se construía: el de

* Chilena, Historiadora del arte, Universidad de Chile y MFA in Curating, Goldsmiths College. Coordinadora de Programas Públicos Museo de la Solidaridad Salvador Allende. Contacto: sgarciasaa@gmail.com 
los manifestantes. En Chile, las alzas exuberantes de las tarifas del transporte escolar, hizo estallar la construcción de barricadas de estudiantes, obreros y pobladores y con ello, la concepción del nuevo poder en la calle. Una nueva comunidad se alzó unificada por el combate contra la injusticia animada por las protestas y el saqueo ${ }^{1}$.

Además de bloquear el avance policial y militar, la barricada históricamente ha sido un divisor de una trinchera temporal de dos territorios; una zona de encuentro del conflicto, donde los cuerpos antagónicos, las fuerzas del movimiento de protesta y la policía, se cruzan, se disputan, se atacan. Las barricadas del 57, además de ser un torpedo que incentivó la violencia, fue el símbolo de los disturbios eminentemente poblacionales del sector sur de la ciudad de Santiago. Y a diferencia de las barricadas de París no contarón con la poesía estudiantil. Las barricadas del 68 se unían al desate de la invención, de la imaginación. El uso poético de la palabra en los muros de París, se inscribió en el sentir y el deseo de frases radicales: "el arte ha muerto, liberemos nuestra vida cotidiana" $\mathrm{o}$ "la barricada cierra la calle pero abre el camino" impactando en la conciencia emancipadora. Los elogios a la barricada como acto audaz de apertura, de libertad, impulsaba el poder de la imaginación, la creación, y por extensión, el hacer la revolución. En ese sentido, la barricada condensa una dicotomía de juegos dobles: la destrucción de un orden impuesto para la construcción de otras alternativas de vida; el quiebre con la continuidad de las reglas modernas de patriarcado y colonialismo subordinado al capitalismo corporativo por la contracultura, la liberación del Tercer Mundo y la eliminación de los nacionalismos.

La barricada fue un actante en latinoamerica y en las artes repercutió en su apropiación violenta y creativa. Desde esa doble confluencia, este ensayo observa la barricada como una alegoría de cambio social que condensa el carácter de distintas trayectorias, materiales y metafóricas, en las artes y la cultura del Santiago en la década de 1960. La barricada es un botín de luchas, cuyas analogías aparecen en las obras, protestas y declaraciones en el pequeño circuito artístico de la capital. Principalmente en los planteamientos artísticos, universitarios y militantes del artista e intelectual Alberto Pérez (1926-1999), quien conjugó una doble trayectoria, práctica y teórica a lo largo de su vida. Profesor de la Escuela de Bellas Artes desde 1953, Pérez fue doctor en Historia del arte y un mentor vital para la enseñanza del arte, la literatura y la política. Fue integrante del Grupo Signo ${ }^{3}$ (1962), participante activo de exposiciones en la Escuela y Bienales (Quito, 1962/1968, La Habana, 1969, Venecia, 1973) y por sobre todo, fue un intelectual en el sentido que lo propone Raymond Williams ${ }^{4}$; es decir, que contribuyó a las reflexiones de su tiempo insertadas en un orden social o en la opinión pública. Escasamente estudiado ${ }^{5}$, el carácter osado de sus pensamientos y acciones se recuerdan en sus clases, en los rastros de sus escritos, en sus obras y en su breve y drástico ejercicio como Director del Museo de Arte Contemporáneo de la Universidad de Chile, entre agosto de 1968 y 1970, para luego abandonar el arte y alistarse en la militancia del Ejército de Liberación Nacional, entrenándose en la táctica guerrillera e instruyendo en la alfabetización y combate a campesinos. Este texto explora las transformaciones de sus obras en esos años, su labor académica en medio de la Reforma Universitaria y su voluntad

\footnotetext{
${ }^{1}$ Gabriel Salazar, La violencia política popular en las “Grandes Alamedas”. La violencia en Chile 1947-1987 (una perspectiva histórico popular), Santiago: LOM, 2006

2 Patricia Badenes Salazar, La estética de la barricada: Mayo del 68 y la creación artística, Castelló de la plana: Universidad Jaume I., 2006, 243

${ }^{3}$ Conformado por José Balmes, Gracia Barrios y Eduardo Martínez Bonati tras la exposición homónima Signo en Madrid en 1962, en una nota del Fondo Alberto Pérez del MNBA, se señala: "El grupo "Signo" de Chile, tiene ya un nombre. Esta exposición su partida de bautismo. Antes de ella, existía una coordinación de esfuerzos, una amistad y un intercambio de ideas. Pero, para nuestra exposición en España, quisimos legalizar la coherencia espontánea de nuestro quehacer, de que algunas exposiciones chilenas fueran partida de nacimiento. Madrid, enero, 1962", Fondo Alberto Pérez, Archivo MNBA.

${ }^{4}$ Raymond Williams, Cultura. Sociología de la Comunicación y del arte, Barcelona: Paidós, 1980, 201

${ }^{5}$ Atender el trabajo de Pérez en este periodo no es una tarea fácil ya que, aunque él donó su archivo al Museo Nacional de Bellas Artes, la organización de sus documentos aún espera de un orden y acceso para la investigación. Por lo que aun existen baches y lagunas que completar sobre su trayectoria.
} 
consciente por ocuparse de la militancia radical. Pérez, movilizará junto a otros agentes culturales, cambios estructurales y sociales en la larga década del 60 que se clausura con el golpe de Estado de 1973.

De esta manera, este ensayo propone una aproximación histórica de tres momentos de la vida y trabajo de Pérez a partir del hilo conductor de los usos de la barricada, -desde la génesis hasta el ocaso de sus levantamientos revolucionarios. Se sostiene una lectura cercana a la posición política de Pérez, quien ejercitó una conciencia social, universitaria y aguerrida de extrema izquierda plasmada en sus obras y escritos. Divido en tres secciones, este texto introduce el panorama de las artes visuales en el contexto de las reformas estructurales que se agudizan en 1964, observando los cambios de los lenguajes en el arte popular y reparando en las militancias de izquierda de los artistas. Insertado en un ambiente de conciencia radical, las barricadas de Alberto Pérez son analizadas desde los enfrentamientos populares, las consignas e invocaciones revolucionarias que se materalizan en primer grado, en su trabajo pictórico y teórico. Un segundo momento, atiende a la defensa universitaria pública y latinoamericana cuando ejerció la dirección del Museo de Arte Contemporáneo en 1968, y los altercados ideológicos entre el sector progresista de inclinación social y el conservador mercantilista cultivador de un gusto foráneo e indiferente de los conflictos. Se finaliza con la adherencia de Pérez a la militancia armada y su distancia parcial del arte en los años de la Unidad Popular para cerrar con el desplome brutal de la democracia y la libertad ante el ataque al gobierno de Salvador Allende y la usurpación de poder de la Junta Militar.

\section{Primera conciencia en las barricadas callampas}

El circuito artístico a fines de la década del sesenta, estuvo compuesto por una convivencia de nuevos medios, espacios alternativos y galerías, unido a las transformaciones que afectó a la institucionalidad artística, principalmente a la Escuela de Bellas Artes de la Universidad de Chile y la recientemente fundada Facultad de Artes de la Universidad Católica. Atravesando los espacios institucionales y alternativos, los artistas Guillermo Núñez y Patricia Israel exhibieron sus obras desde las distintas vertientes del "Arte popular". Por una parte, Núñez desarrolló explosivas pinturas de denuncia mediante corporalidades ahuesadas, gritos y colores planos de carácter Pop despertando las sensaciones de destrucción, horror y muerte frente a las víctimas de la guerra de Vietnam. Por otra parte, junto con Israel se aventuraron en emprendimientos comerciales, al ofrecer a bajo costo la reproducción de afiches "populares" de artistas internacionales como The Beatles y el folklore en Chile de los cantautores Víctor Jara, Angel Parra y la recientemente fallecida Violeta Parra, en la tienda "Poster shop" en el Barrio Bellavista. Las distintas versiones de lo popular, cobraron otro estatuto con las acciones relámpago de la Brigada Ramona Parra, con sus murales en la calle y el compromiso con un arte del pueblo. A esa conjunción amplia de lo popular, se sumaba el arrojo de algunos artistas por experimentar con materiales y sustancias para generar otras sensaciones artísticas. En 1968, coexistieron exhibiciones que reflexionaban sobre las transformaciones del ser humano y la ciencia; como fármaco aséptico en las esculturas-laboratorios de la artista Valentina Cruz en la Galería Patio, o como experimentos liberadores de creatividad mediante el happening y la sicodelia al utilizar los jóvenes artistas drogas, como en la exposición Arte LSD en la Casa de la Luna ${ }^{6}$.

${ }^{6}$ Ver "Inaugurada muestra de experimentación científica. Cuadros inspirados por droga LSD", El Mercurio, Santiago: 30 de agosto de 1968 y "Arte psicodélico: expresión auténtica o ¿una moda importada?, La Nación, Santiago: 2 de septiembre de 1968. 


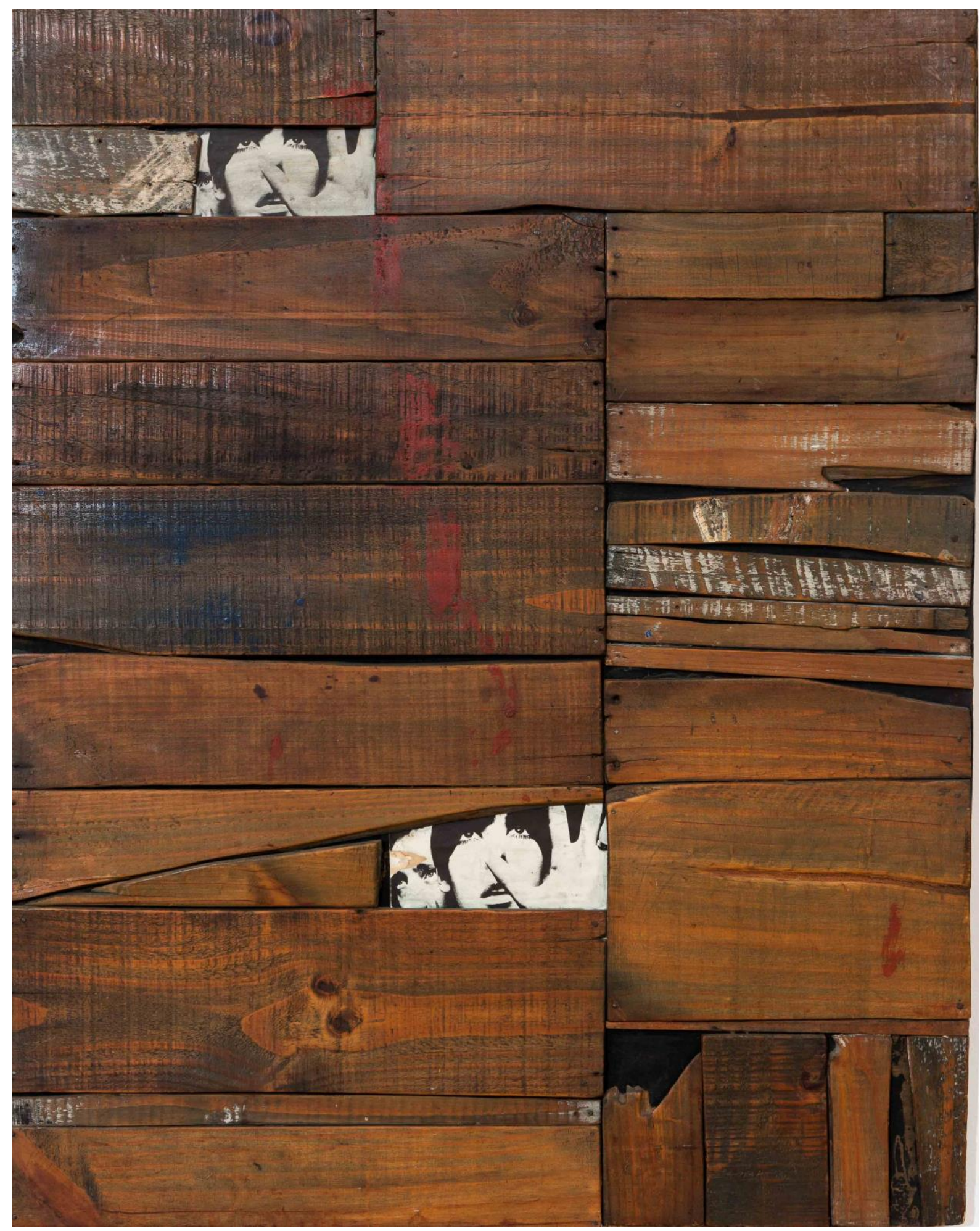

Alberto Pérez, Barricada II, 1965, Colección y gentileza Museo Nacional de Bellas Arte 
En paralelo a estas irreverentes expresiones y lenguajes artísticos, la agitación política de huelgas, tomas y marchas de pobladores, obreros y estudiantes, determinaba también la adhesión a partidos de izquierda o la participación de militancias sociales por parte de los artistas, quienes solidarizaron con las masas postergadas y su estado de pobreza económica y cultural. La tendencia de la ciudadanía ilustrada, tal como lo señala el historiador Gabriel Salazar, "tendía a privilegiar su militancia social por sobre su militancia partidiaria"7. En ese sentido y aun cuando artistas como Guillermo Núñez militaron en el Partido Comunista (PC) y otros como Francisco Brugnoli, Virginia Errázuriz o Félix Maruenda apoyaban mediante sus exposiciones e intervenciones la emancipación de los trabajadores desde su participación en el Frente de Acción Popular (FRAP), lo cierto es que los artistas en su mayoría tendieron hacia un apoyo moral y social más que una retórica dogmática de partidos ${ }^{8}$.

Una de las obras que marcó esa tendencia es la barrera realizada por Virginia Errázuriz llamada 2,2,2. A partir de una valla de defensa, la artista materializó la amenza ideológica de la candidatura a la presidencia de Eduardo Frei Montalva en 1964, en un ensamblaje triangular de listones de madera sobre los cuales incorporó pintura roja y textos como "peligro", "222", "Frei Frei". Los números aludían al registro electoral de Frei quien siendo, representante del Partido Democrata Cristiano, disputó la candidatura presidencial entre otros, con Salvador Allende, candidato de la coalición de partidos de izquierda, FRAP. En medio de la campaña conservadora y anticomunista de Frei Montalva, conocida como la "campaña del terror", Errázuriz realizó esta obra en los últimos años de sus estudios en la Escuela de Bellas Artes de la Universidad de Chile, denunciando la agresividad política del programa de Frei Montalva. El peligro que observó Errazuríz, era el control social de las masas populares a través de un gobierno con interés empresarial que se camuflaba en un Estado democrático.

Con el propósito de salir del estancamiento económico, el gobierno de Frei Montalva ejecutó reformas estructurales para modernizar las industrias. A partir de 1964, dio continuación al programa de la Alianza por el progeso impulsado por el presidente John F. Kennedy para prevenir la amenaza de una izquierda revolucionaria en toda América Latina; profundizó la Reforma Agraria a partir de 1967, iniciada por su antecesor, el presidente Jorge Alessandri. Agilizó la expropiación de predios para ser trabajados por el campesinado con el objetivo de incrementar la productividad agrícola y sus condiciones salariales y, diversificó las exportaciones no solo hacia Estados Unidos, también hacia Europa y Japón?. En 1968, en medio de un clima de agitación social tanto en las zonas rurales por las tomas de fundos ${ }^{10} \mathrm{y}$ urbanas por las movilizaciones obreras y estudiantiles, se intensificó el proceso de Reforma universitaria o el pilar de un nuevo modelo que buscaba, según el plan de Frei Montalva, la profesionalización para enfrentar una sociedad industrial. El instrumento volcó las viejas estructuras que centralizaba la toma de poder y decisiones administrativas y académicas por un sistema descentralizador a nivel nacional. Sin embargo al perfil de una universidad profesionalizante integrado a la economía, suscitó la oposición en el sector más progresista, que defendía el rol abierto a todos los sectores sociales, al servicio del pueblo ${ }^{11}$. Esta disyuntiva obtuvo en la Facultad de Bellas Artes de la Universidad de Chile un carácter transformador no solo en la reorganización administrativa y académica en el país, sino que también en sus querellas filosóficas y estéticas frente a las convenciones y reglas del

\footnotetext{
7 Gabriel Salazar, La violencia política popular en las “Grandes Alamedas”. La violencia en chile 1947-1987 (una perspectiva histórico popular), Santiago: LOM, 245

${ }^{8}$ En el caso de Guillermo Núñez, la irregularidad de su militancia en el Partido Comunista coincide con la Ley Maldita y la prohibición de la militancia comunista. No existiendo registro formal como militante, las reuniones y pagos de cuotas se hacian camufladamente a través del "Club Deportivo Atlético "David Arellano". A partir de 1961 y luego de regresar de un viaje a Checoslovaquia, Núñez dejó de asistir a las reuniones y optó por renunciar al Partido, sin quedar registro alguno de inscripción y desinscripción. Agradezco a Guillermo Nunez e Isidora Neira por esta aclaración.

${ }_{9}^{9}$ Gabriel Salazar, Julio Pinto, Historia contemporánea de Chile III. La economía: mercados, empresarios y trabajadores, LOM: Santiago, 96-115

10 op.cit., 114

11 Osvaldo Cazanga Moncada, Historia crítica de la educación pública en Chile, Rialstat Editores: Santiago, 2017, $223-266$
} 
arte, la formación y el rol de los artistas, la relación más estrecha con los problemas de la vida social, la gestación de acciones culturales hacia la calle, la insubordinación al capitalismo corporativo en la educación, el compromiso, la denuncia y el trabajo junto a los más explotados.

Alberto Pérez, Barricada III, 1965, Colección y gentileza Museo Nacional de Bellas Artes

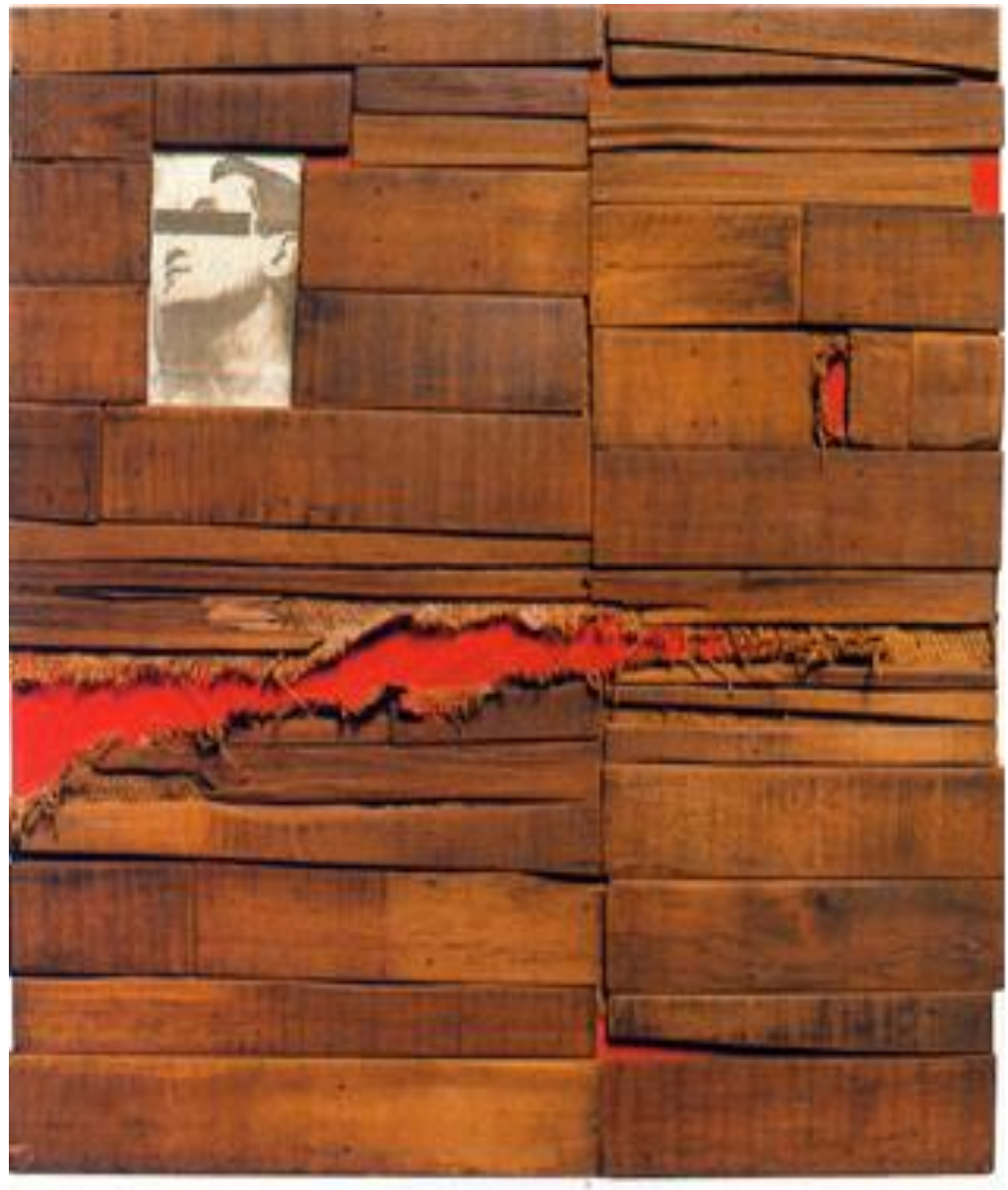

Esta conciencia radical $^{12}$, resonó en el curso de las contingencias políticas $\mathrm{y}$ sociales por estrechar el arte con la vida. Y se plasmó en el inconformismo de los propios medios modernos de las Bellas Artes, el culto burgués de la pintura de caballete. El viraje prerevolucionario que se fraguó a mediados de los años sesenta en las artes locales, estimuló una inmersión en la realidad, un compromiso con las problemáticas sociales del propio tiempo y la expresión de un evidente y auténtico rostro local. Desde esa posición, las obras de Alberto Pérez a partir de 1964, trazaron una sensibilidad comprometida con las expresiones de los pobladores, sus frustraciones y agresividad. Su trabajo se tornó en una confrontación pictórica, que buscaba sacudir los ropajes prestados de la representación de una realidad por incluir la realidad en el propio cuadro.

Así, en medio de los modelos antagónicos de libertad que la Revolución cubana avivó y las campañas anticomunistas para los trabajadores en Chile ${ }^{13}$, las obras de Pérez se aproximaron metafóricamente a las luchas de los pobladores de campamentos, cuyas deplorables condiciones de vida, hacinamiento y miseria en las "poblaciones callampas" en Santiago evidenciaban, por una parte, la realidad de pobreza, inequidad y marginación social y, por otra, la realidad brutalmente violenta, al protestar y defender sus campamentos con barricadas hechizas de maderas y desechos frente a la represión de la policía. El conjunto de obras que Pérez denominó como Barricadas, plasmó esos rastros de las fuerzas de combate colectivas, la destrucción y la muerte producida por balaceras. Las barricadas de Pérez fue una serie de obras que parte con Bandera guerrillera de 1964 y que se cierra con Bandera de

\footnotetext{
${ }^{12}$ Herbert Marcuse, Un ensayo sobre la liberación, Edición Joaquín Mortíz S.A: México, 1969, 37

${ }^{13}$ Marcelo Casals A. "Chile en la encrucijada". Anticomunismo y propaganda en la "campaña del terror" de las elecciones presidenciales de 1964”, Chile y la Guerra Fría, Eds., Tanya Harmer, Alfredo Riquelme Segovia, Santiago: Ril Editores, 2014, 89-112
} 
Lonquén de 1985, luego del hallazgo público de quince cadáveres de pobladores y campesinos en una mina de cal en Lonquén en 1978. Según sus distintos contextos, antes y después del golpe militar, las banderas de estas barricadas, buscaron animar la revolución o levantar un escudo de vida y recuerdo de muertes que para otros ya no tendrán ningún efecto.

Las construcciones de las barricadas rompieron con los esquemas tradicionales del cuadro, la vigencia del "hacia adentro" de la pintura y el reemplazo de la tela-bastidor por la integración a la superficie de "cosas": objetos sobrantes, maderas viejas de tabiques de mediagua o cajas de feria, telas rasgadas y fotografías intervenidas. En los orificios de las barricadas, Pérez integró fotografías y fotocopias en blanco y negro, que repiten la impresión de ojos entreabiertos, expresivos y asombrados que generan la sensación de confrontar o rechazar una realidad. La importancia de la mirada corresponde a una de las distintas capas semánticas de las barricadas que pueden comprenderse desde las lecturas existencialistas que Pérez realizó sobre el escritor argelino Albert Camus.

En el año 1965, Pérez publicó en la Revista de Filosofía un ensayo sobre la Concepción del arte y la visión del artista en Camus donde meditará sobre el primer libro del autor El revés y el derecho escrito en Praga en 1937. Este libro Pérez lo leyó en Santiago, traducido al español, cuando Argelia recién se recompuso de la guerra. Y tendrá un especial interés por las ideas de Camus en torno a los dos lados que coexisten y contrastan en la vida. Por una parte, un lado correcto representado por la explosión de sensaciones de felicidad que uno puede sentir al estar con los demás y encontrar su lugar en el mundo, y por otra parte, un lado incorrecto, representado por la desesperanza que uno siente cuando contempla la vida, sobre todo por el pensamiento de no poder impedir la muerte inevitable. El gran coraje para Camus es aceptar y mirar ambos lados, sobre todo el destino que está de frente que es la muerte. En ese sentido, en los ojos y rostros que selecciona Pérez para sus barricadas se encuentran desde las más perfectas musas de la revolución de la moda de la década de 1960 como Peggy Moffitt o quien podría ser la supermodelo Twiggy, hasta la figura del Che Guevara, en la desaparecida barricada de 1968.

La barricada Homenaje al Che fue una apología al héroe guerrillero asesinado en Bolivia y una antesala para comprender las situaciones prerrevolucionarias en el arte: los llamados de Pérez de nutrirse de una realidad latinoamericana. Tales declaraciones fueron exploradas en su texto "La pintura cubana en la revolución", publicado en la Revista Atenea en 1970, donde cuestionó la imposición de las ideologías capitalistas de Estados Unidos en los países latinoamericanos y abrazó, con admiración, los cambios políticos que se construían en Cuba al avanzar hacia un modelo de liberación común -desde una sociedad socialista hacia el comunismo. La importancia de la figura del Che Guevara concentró para Pérez "la inspiración más original de revolución en la historia y la orientación para los objetivos prerrevolucionarios" en países que aun no habían alcanzado la rebelión para suplir "aquellas necesidades incumplidas del proletariado y campesinado", ${ }^{14} \mathrm{y}$ "reconquistar la dignidad" a través de la vía socialista como es el caso de Chile. Pérez, alentó a los intelectuales, -a quienes tildó de burgueses de nacimiento o de elite-, a asumir el deber y el peso de "forjar el hombre nuevo en la lucha armada y en la movilización de la conciencia de las masas postergadas" 15 . Este deber fue apuntado por Pérez como la primera realidad de América y significó como requisito, la necesidad de transformar la relación protectora y paternalista del intelectual con las masas. A su vez, esta nueva directriz guerrillera en el arte, contó con resonancias contradictorias. Una de las principales contradicciones que Pérez vivió y observó fue la incapacidad de excluirse de la invasión ideológica norteamericana cuya política cultural colonialista o simplemente comercial "lo tragaba todo" en defensa de que las nuevas tecnologías solucionaban los problemas del pueblo. Por otra parte, Pérez reflexionaba sobre las porosidades inevitables que sus atractivas mercancías y también tendencias artísticas ofrecían a los intelectuales, siendo tentados a replicar estas obras o "mimetizar estas estéticas para no quedar marginados" evitando

${ }^{14}$ Alberto Pérez, La Pintura cubana en la revolución, en Revista Atenea, 10

15 Pérez, op. cit., 9 
ser catalogados en las llamadas derivaciones, copias, dependencias artísticas o "colonialismo intelectual" 16. En oposición a las estructuras impuestas por intereses foráneos, la realidad de los intelectuales en América estaba motivada en cambio, por la creación de nuevas formas que pudieran interpretar lo propio: "los sufrimientos del pueblo, la conciencia del ser explotado, perseguido y humillado" 17 . Pérez señalaba, asímismo, que nuestra realidad "responde a una sociedad que despierta" como una "nacionalidad configurada de americanidad bolivariana" 18 y que tendrá que ser formulada por una política radical.

\section{La barricada por Cuba. Del programa abstracto del MoMA a las vallas cubanas}

Con un tono de anarquismo, las declaraciones de Pérez fueron encarnadas a partir de 1970 cuando convivió y se sumergió en la cooperación armada con lo trabajadores de extrema pobreza en los fundos del sur de Chile. En el intertanto, los debates sobre el auge de la sociedad de consumo, la dependencia colonial de empresas y las filiaciones norteamericanas en el ámbito educativo y artístico, fueron enfrentados en medio de la implementación de la Reforma Universitaria de la Facultad de Bellas Artes de la Universidad de Chile, en especial, a través del faro público de las tendencias actuales del arte: el Museo de Arte Contemporáneo.

La Facultad de Bellas Artes de la Universidad de Chile, ubicada en ese tiempo en lo que es el actual Museo de Arte Contemporáneo del Parque Forestal y dirigida entonces por el pintor José Balmes, logró actualizar los programas de estudios por medio de la Reforma. En ese contexto se crearon los departamentos de Teoría y Pedagogía y el Centro de Estudios de Arte Latinoamericano ${ }^{19}$ y se unificó la licenciatura en arte para aquellos estudiantes considerados previamente como artífices y artesanos. Se agregaron cátedras de tecnología, de diseño y experimentación con otros materiales industriales.

Activo y comprometido con el movimiento de la comunidad universitaria, Pérez participó con gran dedicación y pasión por esta causa, declinando a invitaciones extendidas desde la Habana, para enfrentar los rápidos y profundos cambios en los talleres y cátedras para "acabar con el autoritarismo universitario"- como recuerda Pedro Miras, quien fue a partir de 1968 el decano de la Facultad ${ }^{20}$.

Inseparable de la Facultad de Bellas Artes, se encontraba el Instituto de Extensión de Artes plásticas dirigido por el escultor Abraham Freidfeld. El Instituto tuvo la misión de establecer las directrices de las investigaciones, las exhibiciones, las publicaciones, los foros y la planificación de la docencia en torno al arte nacional en las distintas sedes universitarias a lo largo del país ${ }^{21}$. En la jerarquía de la Facultad, el Instituto canalizaba su programa a través del Museo de Arte Popular (MAPA), el Museo de Arte Contemporáneo (MAC) y la Sala Universitaria en la Casa Central de la Universidad.

El MAC se encontraba subordinado a una directiva integrada por el Instituto de Extensión de Artes Plásticas que en 1970 pasó a llamarse Instituto de Arte Latinoamericano. Este Instituto también sufrió en 1968 un cambio en su dirección con la designación de Abraham Freidfeld para reemplazar la

\footnotetext{
16 Pérez op.cit., 20

${ }^{17}$ Pérez cita a Camilo Torres, el cura guerrillero, militante del Ejercito de Liberación Nacional en Colombia.

18Pérez op.cit.,15

${ }^{19}$ Artículo, Bellas Artes...recuento del año 69 en el MAC e Instituto. Fondo Alberto Pérez, Archivo MNBA.

${ }^{20}$ Pedro Miras, Alberto Pérez en la Reforma universtaria, Revista Electrónica de Arte, REA, 2008, s/n

${ }^{21}$ El Instituto de Extensión de Artes Plásticas de la Universidad de Chile, fue creado por decreto el 27 de Junio de 1945 por del Ministerio de Educación, con el objetivo de estudiar, difundir y estimular las Artes Plásticas Nacionales. Atendió, además, al intercambio artístico con el extranjero y fue un organismo técnico consultivo al servicio de la Universidad y demás organismos oficiales que solicitaban su colaboración. Transcripción del Artículo ${ }^{\circ}$ del Reglamento, Decreto No 425, de abril de 1946, de la Universidad de Chile.
} 
gestión de Jorge Elliot. La directiva de recambio, se completaba con José Balmes, como director de la Facultad de Bellas Artes y Pedro Miras, como decano de la Facultad, quien reemplazó a Luis Oyarzún. Todos ellos trabajaron en el programa y principios de la Reforma.

En ese proceso, el Instituto replanteó su rol estructural con la nación, cuestionando la formación de profesionales-funcionarios que respondieran a la inserción laboral capitalista, a la dependencia de ideas importadas, a la concepción de un arte autónomo y anquilosado en una tradición para una elite. El deber en cambio, consistía en quebrar drásticamente con estas antiguas estructuras para formar intelectuales comprometidos que catalizarían una "participación directa y activa de la creación" con el fin de confrontar "los problemas de una realidad (propiamente) latinoamericana ${ }^{22}$. En un ambiente de ruptura con los valores extranjeros de corte imperialista, el Instituto enfatizaba la formación de un intelectual íntegro que pudiese "activar la conciencia" en la sociedad ${ }^{23}$.

En lo que refiere a estos valores bajo el alero de una bandera latinoamericana, los otros espacios donde van a propagarse estos lemas, serán en los museos y en especial, las exposiciones. En el caso del MAC, serán las muestras las que van a permitir dirigir el rumbo latinoamericano y las "mediaciones" incipientes con "el pueblo".

La repercusión de la Reforma universitaria y las transformaciones declaradas por el Instituto, tuvieron una clara incidencia en el giro de la dirección del Museo de Arte Contemporáneo, ubicado en la Quinta Normal. Alberto Pérez fue director del Museo durante dos años, entre agosto de 1968 y agosto de $1970^{24}$. Este periodo corto de liderazgo, compartido con los distintos directivos y representantes de los departamentos de la Facultad en la toma de decisiones, marcó un cauce de trabajo colectivo, determinado por una especial apertura para acoger las prácticas de artistas nacionales y latinoamericanos, con exposiciones de arraigo local y popular, coexistiendo muestras de arte infantil y experimental y ofreciendo cursos vespertinos de perfeccionamiento artístico, artesanal y profesional a los obreros de la Central Única de Trabajadores (CUT) ${ }^{25}$. Pérez se empeñó en revertir y abrir el imaginario artístico de su tiempo, forjando otra dirección en la sociedad en base a la concepción de un imaginario colectivo anticolonial. Estos ideales obedecieron, por una parte, a una nueva actitud de estudiantes y docentes generando puentes de comunicación con el pueblo a través de sus obras, exposiciones y programas de formación. Por otra parte, a una resistencia a la instrumentalización de bienales ${ }^{26}$, exposiciones o premios auspiciados por la empresa privada ${ }^{27} \mathrm{o}$ los subsidios provenientes por presupuestos locales como la Sociedad Amigos del Museo de Arte Contemporáneo ${ }^{28} \mathrm{O}$ internacionales como el Consejo Internacional del Museo de Arte Moderno de Nueva York, MoMA.

22 Copia borrador del Informe, Comisión de Función, Fondo Alberto Pérez, Archivo MNBA

23 op.cit, s/n

${ }^{24}$ En una carta enviada al decano Pedro Miras, Pérez deja su cargo el 1 de agosto de 1970, Fondo Alberto Pérez, Archivo MNBA

${ }^{25}$ Ver convenio CUT e Instituto de Extensión de Artes Plásticas, Serie Correspondencia, FAIMAC, Archivo Institucional MAC. El programa del Instituto buscó generar acuerdos con la Comisión de Cultura de la CUT, a través de Jorge Godoy, quien además conectó con los Sindicatos de Chilectra, Cuero y Calzado y construcción. Ver: Acta N¹4. Consejo Co-directivo, martes 14 de octubre de 1969. Serie Correspondencia, FAIMAC, Archivo Institucional MAC.

${ }^{26} \mathrm{La}$ Facultad se opone a la persecución de los artistas e intelectuales de Brasil, y protesta con el retiro del envío nacional a la Bienal de Sao Paulo, conocida como la "Bienal Gorila". Recuento Bellas Artes, 1969. Fondo Alberto Pérez, MNBA.

${ }^{27}$ Con el fin de prevenir manifestaciones de los estudiantes contra el premio anual de pintura y escultura auspiciado por la empresa Compañía de Refinería de Azúcar de Viña del Mar, conocido como Premio CRAV, la empresa arbitrariamente convocó a la policia sin consulta previa al director Alberto Pérez, lo que significó un atropello a la autonomía universitaria y el fin de las colaboraciones entre el MAC y la empresa CRAV a fines de 1968. Posterioremente, los premios se llevaron a cabo en el Museo Nacional de Bellas Artes. Recuento Bellas Artes, 1969. Fondo Alberto Pérez, MNBA.

28 Agustín Edwards era miembro del directorio de la Sociedad Amigos del Museo de Arte Contemporáneo de Santiago, órgano ideado por el artista Nemesio Antúnez, director del Museo de Arte Contemporáneo entre 1962 y 1964. Integrado por empresarios como Flavián Levine, José Klein y Salvador Pubill, encargado de finanzas de la campaña de Frei Montalva, y políticos y empresarios como Germán Picó, miembro del Partido Radical, Gabriel Valdés, miembro del Partido Demócrata 
Una pugna local con alcances internacionales fue la exitosa y polémica exhibición De Cezánne a Miró. Este fue un conjunto de obras, reunidas estratégicamente que hoy, mediante los archivos y las nuevas lecturas sobre las complicidades ideológicas del MoMA con la CIA en medio de los enfrentamientos de la Guerra Fría ${ }^{29}$, puede leerse desde una formulación educativa para despolitizar al arte y al público a través del recurso de los grandes maestros modernos del arte. La exposición realizada entre el 26 de junio y el 17 de julio en el MAC de Quinta Normal, organizada en Santiago por su director de entonces, el escultor Federico Assler, auspiciada por el diario El Mercurio y patrocinada por el Ministerio de Relaciones Exteriores, constituyó un éxito mediático alcanzando un record masivo de público, con más de 218.000 visitas -cuatro veces más de la capacidad que tiene actualmente el Estadio Nacional en Santiago-, y con un horario continuo de apertura desde las 13:00 hrs hasta las 12 de la noche todos los días, transformándose en la exposición más recordada del siglo XX en Santiago. Para el MoMA esta exposición fue un hito al consagrar sus relaciones con Latinoamérica a través de su Programa de Exposiciones Internacionales, al itinerar esta exposición por Caracas y Buenos Aires y ser la sexta muestra de su colección internacional en Chile ${ }^{30}$. Las obras de la colección del MoMA constituían una elección discursiva de los grandes maestros de la abstracción moderna y el canon historiográfico del arte europeo; un relato que provenía de las genealogías formalistas y cohesivas de Alfred Barr, el primer director de este museo, quien forjó un nuevo paradigma de museo-escuela con "pronunciamiento normativo" e "identidad corporativa" desde 1929 hasta 1967. Tal como lo analiza Karsten Schubert, "para el Consejo directivo, Barr había desarrollado la imagen de la colección del museo como un torpedo: empujó 'un marcado avance del presente, cuya trinchera era su retroceso en el pasado"'31.

La elección de estas exposiciones "cometa" en el MAC de Santiago no obedecían a decisiones azarosas, más bien respondían a la expansión del arte norteamericano con capitales privados. En el caso de Chile, exhibir los grandes maestros de la abstracción moderna constituyó un hito que estimuló otros programas de itinerancia y un instrumento eficaz para apartar todo atisbo revolucionario como el modelo cubano. La abstracción, tal como lo señala la historiadora del arte Andrea Giunta, será un “"lenguaje puro" capaz de diluir los conflictos que la vida pública podría acarrear saltando por encima los contextos y situaciones históricas específicas. El arte abstracto y no la figuración, podía cumplir esta tarea" 32 .

No existen certezas de que los artistas en el año 1968 hayan percibido la instrumentalización que se hacía del arte con las exposiciones de tendencia moderna, lo que si era evidente fueron las intervenciones directas que el Consejo Internacional del MoMA ${ }^{33}$, y en especial de Agustín Edwards, dueño del diario El Mercurio y miembro del directorio de la Sociedad de Amigos del MAC, respaldaba

Cristiano y luego Ministro de Relaciones Exteriores de Frei Montalva, Sergio Larraín García Moreno, arquitecto, decano de la Pontificia Universidad Católica y embajador de Chile en Perú en el gobierno de Frei Montalva y funcionarios de la Facultad de Bellas Artes, como Luis Oyarzún, y Jorge Elliot, participaron en una empresa que daba las directrices del Museo de Arte Contemporáneo de la Universidad de Chile. Ver Sociedad Amigos del Museo de Arte Contemporáneo de la Universidad de Chile, Santiago: Editorial Universitaria, 1966. http://www.memoriachilena.cl/archivos2/pdfs/MC0069933.pdf. Acceso: $5 / 05 / 18$

${ }^{29}$ Frances Stonor Sounders, Who Paid the Piper?: The CLA and the Cultural Cold War, London: Granta, 1999

30 De Cézanne a Miró, International Council of the Museum of Modern Art, New York. Museo Nacional de Bellas Artes, Buenos Aires, Museo de Arte contemporaneo Santiago, Museo de Bellas Artes, Caracas, 1968

31 Karen Schubert, The Curators's Egg, The evolution of the museum concept from the French Revolution to the present day, London: Ridinghouse, 2000, 47. La traducción es mía.

32 Andrea Giunta, Vanguardia, Internacionalismo y Politica. Arte argentino en los años sesenta, Buenos Aires: Siglo veintiuno editores, 2008, 246.

${ }^{33}$ Malú del Río, esposa de Agustín Edwards, en la entrevista a Sharon Zane señala que perteneció al Consejo Internacional del MoMA desde la exposición De Cézanne a Miró de 1968 hasta 1998, invitada por David Rockefeller, empresario banquero, coleccionista y amigo de Edwards. Sharon Zane, MoMA Archives Oral History, New York: MoMA, 1994, https://www.moma.org/momaorg/shared/pdfs/docs/learn/archives/transcript edwards.pdf 
y financiaba con sus fondos privados la envergadura de la producción de una exposición de este tipo, en un museo público y universitario. La controversia que se desató posteriormente a la exposición De Cézanne a Miró, puso término a la alianza entre el MAC, el MoMA y la Sociedad de Amigos del Museo. No obstante, las exposiciones del MoMA encontraron otra plataforma cultural para sus itinerancias y alianzas a través de las salas del Museo Nacional de Bellas Artes de Santiago en 197034.

Los usos del MAC como sede de intereses privados desvinculados de su misión pública, indignaba internamente a la junta directiva del Instituto, principalmente al artista Eduardo Martínez Bonati y al decano Pedro Miras, quienes acusaban las irregularidades administrativas, el usufructo ilegal y el intervencionismo con fondos inadecuados ${ }^{35}$. La polémica que gatilló estas acusaciones fue la visita de una comitiva de dieciocho directivos del Consejo Internacional del MoMA a Santiago en el mes de octubre y la organización de una exposición especialmente preparada para los altos directivos norteamericanos por Assler sobre artesanía en el MAC ${ }^{36}$; una muestra que no contaba con el conocimiento ni la aprobación del Instituto. Por esa razón, Alberto Pérez es designado director del MAC en agosto de 1968, representando un punto de inflexión con respecto a las exhibiciones provenientes de Nueva York, para dar paso a un cambio de las relaciones internacionales culturales enraizadas principalmente en Latinoamérica, y con especial énfasis en las practicas artísticas llevadas a cabo en Cuba.

Este giro radical y directo hacia Cuba, se ligaba desde inicios de la década de 1960 con las invitaciones que realizaba la Casa de las Américas de la Habana a participar de las Bienales de grabado y las distintas ediciones de la Exposición de la Habana a los artistas chilenos ${ }^{37}$. Pérez fue invitado como Jurado del certamen de la Exposición de la Habana a inicios de 1968, sin embargo, concentrado en la Reforma universitaria de la Facultad, descartó la invitación hasta el año siguiente al ser nuevamente invitado a la Bienal de la Habana como parte de la comisión del certamen.

De la experiencia de esa visita, la participación en los foros con artistas cubanos, y su conocimiento de la obra de Raúl Martínez, el entusiasmo de Pérez hacia Cuba se manifestó en su extenso ensayo ya comentado, La pintura cubana en la revolución. Para Pérez la creación de los artistas era vital para "dinamizar lo vivo, redescubrir, mirar de nuevo, re-conocer el mundo" 38 hacia una expresión propia y movilizar las conciencias de las masas postergadas, principalmente los obreros y campesinos, sin implantaciones audaces, ajenas y alienantes.

Este pensamiento simpatizaba con figuras y medios que alentaron las revoluciones frente al rechazo de la "paz americana" promulgada por Estados Unidos, y fue uno de los derroteros que condujo los nuevos criterios latinoamericanistas del MAC. Asimismo y aun cuando el MAC dio continuidad a la programación definida por Assler como la exposición Arquitectura fantástica (Visionary architecture) perteneciente a la colección del MoMA, la nueva impronta del año 1969 estuvo sujeta a la integración del arte, a la realidad social con exposiciones que iban desde la protesta y el desarrollo de talleres artísticos como Homenaje a Ho Chi Minh, presidente guerrillero muerto por la lucha de la liberación de Vietnam y representante para Pérez de los pueblos combatientes, hasta Vallas Cubanas, a partir del envío de la Casa de las Américas de la Habana de carteles ubicados entre la calle y el campo de Cuba. Ambas exposiciones acompañadas de actos culturales, música, foros o proyecciones de

\footnotetext{
${ }^{34}$ MoMA, International Circulating Exhibitions: https://www.moma.org/momaorg/shared/pdfs/docs/learn/icelist.pdf

35Ver documento sesión ordinaria de la junta directiva del Instituto de Extensión de Artes Plásticas, 23 de abril de 1968, Serie Correspondencia, FAIMAC, Archivo Institucional MAC.

${ }^{36}$ De acuerdo al mismo documento de la sesión ordinaria, se menciona al curador Waldo Rasmussen del MoMA, sin mencionar los nombres o la asociación a los dieciocho altos directivos.

${ }^{37}$ Las correspondencias entre la Casa de las Américas en La Habana se inician con las invitaciones a participar del Primer Concurso Latinoamericano de Grabado en 1961 y luego a la Bienal de Grabado en 1965, dirigidas al artista Mario Toral. Ver correspondencias entre Casa de las Americas, Archivo MSSA.

38 Alberto Pérez, La Pintura cubana en la revolución, en Revista Atenea, 10
} 
películas al aire libre ${ }^{39}$, se materializaron como los primeros encuentros solidarios con las contingencias políticas de Vietnam y Cuba, respondiendo a la urgencia de incidir con nuevos lenguajes en la conciencia de los visitantes, aquellos hombres y mujeres humildes que paseando por la Quinta Normal se introducían en las contrastantes disputas polares de la Guerra Fría: por una lado, los símbolos de la guerra, la muerte y la destrucción colonial y en el segundo caso, la vitalidad de la unión latinoamericana desde Cuba.

Como referente especial, la exposición Del Tercer Mundo, celebrada en la Habana en 1968, fue para Pérez un hito que compatibilizaba la calidad plástica en técnicas comerciales como el cartel, las portadas de libros, las revistas, las serigrafías y por, sobre todo, las vallas. Fue en el gran cartel camionero en donde Pérez encontró la unión más contemporánea de la plástica y la política, la originalidad del trabajo colectivo y la proyección de la fantasía, la contingencia, el trabajo y lo cotidiano por medio del color y el diseño ${ }^{40}$. El entusiasmo de Pérez por la creación cubana se enganchó con el cine como con las pinturas, serigrafías y vallas del artista Raúl Martínez, del cual se exhibió en Santiago la valla llamada Nosotros, compuesta por la reunión colectiva de rostros de jóvenes, niños, hombres y mujeres, trabajadores y líderes de la revolución que construián un rompecabezas de diversidad y unión.

Sin embargo, las muestras más ambiciosas en su periodo como director fueron Expresión plástica del niño en Latinoamérica (en diciembre de 1968), muestra en la que contó con la colaboración del Ministerio de Educación, llamando a participar niños y jóvenes latinoamericanos entre los 6 y 16 años con el fin de obtener una imagen global de la expresión infantil y juvenil; y la exposición-concurso Historieta de la política Latinoamericana 1969, cuya evidente ofensiva a la penetración de los valores imperialistas encarnados en el héroe, convocaba a denunciar a los agresores y a crear los tipos latinoamericanos a través del medio popular de la historieta. Posteriormente, para el año 1970, la ambiciosa exposición-concurso estuvo encabezada por América no invoco tu nombre en vano, y la exposición-manifiesto Homenaje al triunfo del pueblo, para finalizar con la celebración de la victoria presidencial de Allende y la reafirmación de la actitud militante y de absoluto respaldo de los artistas chilenos. Para esa exposición, Pérez participó como artista, tras ser relevado en su cargo como director del MAC por el artista Guillermo Núñez a partir de $1971^{41}$.

Estas muestras, fuera del canon hegemónico, más bien referentes de un modelo alternativo de convicciones, continuó hasta septiembre de 1973 con la conducción de Núñez y luego del artista Lautaro Labbé. Estas muestras abrieron preguntas sobre los nuevos valores, principios del arte y del museo al tener como objetivo principal la integración del pueblo. Estas exposiciones podrían permitir interpretaciones de un "contra museo" o de un "anti-museo" como lo propone Martin Grossman ${ }^{42}$; termino acuñado en los años 90 para evidenciar el recambio del museo no para el arte culto de las Bellas Artes sino en su extremo, un museo "con olor a cebolla" 43 como diría Nuñez, para las masas de "pies pelados".

A partir de 1970, Pérez se desapega de su trabajo artístico y universitario en Santiago y solicita un permiso a la Universidad de Chile para ausentarse por dos años ${ }^{44}$ para poder dedicarse activamente en un proceso revolucionario con el sector de trabajadores rurales más pobres y marginados en el sur

\footnotetext{
${ }^{39} \mathrm{El}$ corto Hanoi martes 13 (1967) del cineasta y documentalista cubano Santiago Alvárez se proyectó afuera del Museo. Ver Bellas Artes, 1969.

${ }^{40}$ Alberto Pérez, La Pintura cubana en la revolución, en Revista Atenea, 20

41 Guillermo Núñez, Retrato hablado: una retrospectiva, Santiago: Museo de Arte Contemporáneo de la Universidad de Chile, 1993, 151

${ }^{42}$ Martin Grossman, Giberto Mariotti, Org. Museum art today. Museu arte hoje., São Paulo: Hedra, 2011, (Coleção Fórum Permanente), 90

43 Guillermo Núñez, Retrato hablado: una retrospectiva, Santiago: Museo de Arte Contemporáneo de la Universidad de Chile, 1993, 151

${ }^{44}$ Entrevista de Claudia Zaldívar a Alberto Pérez 6 de octubre de 1990. Archivo Museo de la Solidaridad Salvador Allende
} 
de Chile. Atraído por la conciencia y la lucha guevarista, Pérez encarnará la conversión de un militante de izquierda extrema, radicalizando su labor intelectual al servicio de la ofensiva campesina.

\section{La última barricada: el apoyo al socialismo y su destrucción}

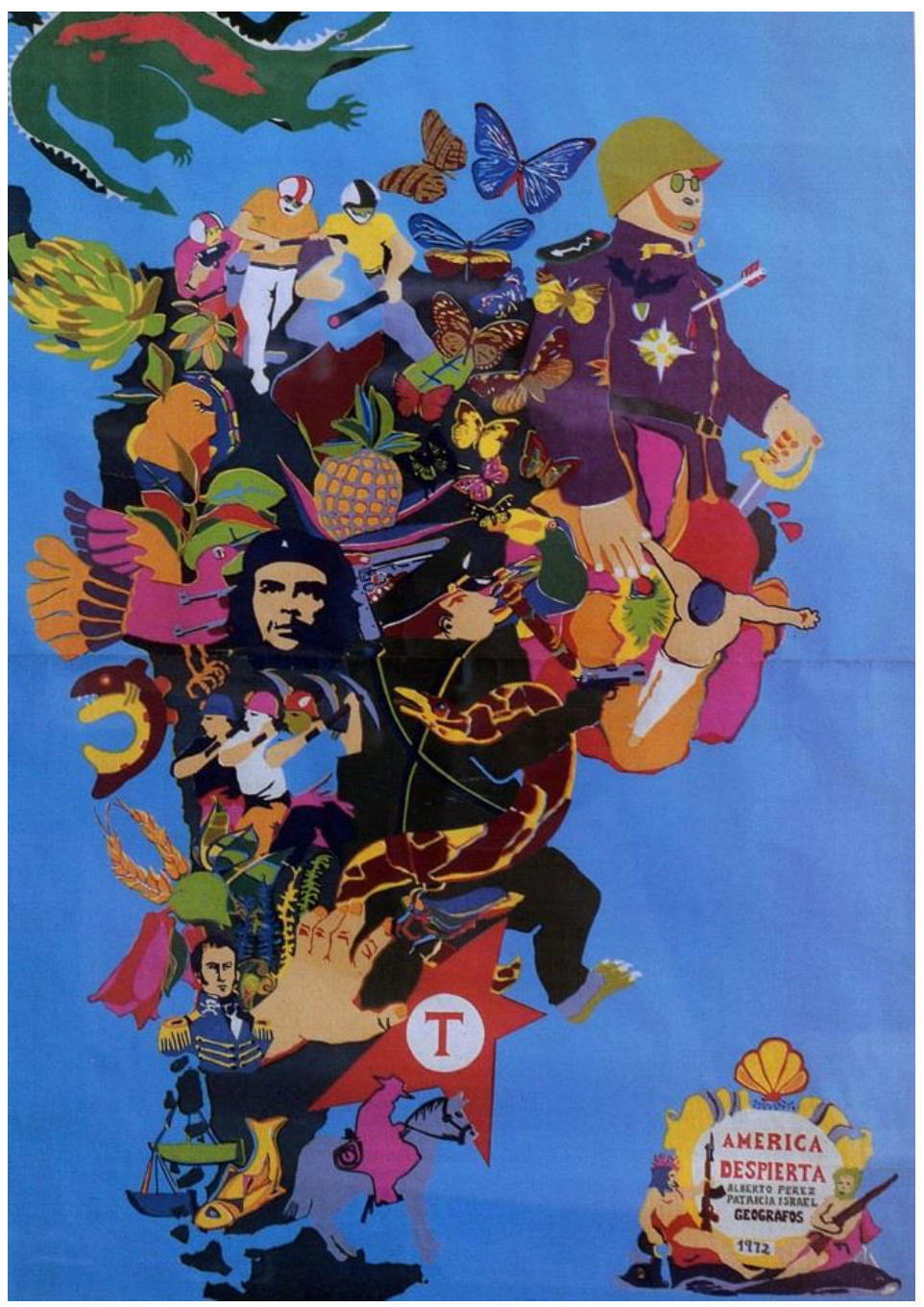

Los problemas tan fútiles como los del arte, la teoría y la burocracia del museo no tuvieron ninguna urgencia al lado de la necesidad de hacer la revolución solidaria. En 1971, Pérez se incorporó a trabajar activamente en el Instituto de Capacitación e Investigación de la Reforma Agraria (ICIRA), un organismo que dependía de la Corporación de la Reforma Agraria y del Ministerio de Agricultura, desde donde él y otros miembros educaron políticamente al campesinado en el entrenamiento de la defensa armada, en especial a los "afuerinos", campesinos muy pobres sin casa que trabajaban ofreciendo sus servicios en los fundos. Desde esta trinchera, Pérez ejerció los lineamientos declarados para los artistas en el Congreso de la Habana de 1968, esto es, relegar el arte "para una vida nueva y mejor" $y$ emprender la lucha armada en defensa de los explotados 45. Ocupándose de esta misión sin titubeos, se incorporó a la militancia socialista y al Ejercito de Liberación Nacional (ELN).

De los escasos rastros de este periodo, se encuentran los testimonios del artista Roberto Matta, quien fue invitado por Pérez para reunirse con distintos afuerinos en los fundos de Los Angeles, Parral y Mulchén. Matta, quien participó del Congreso de la Habana de 1968, definió a los afuerinos como la "mano de obra gitana que hay en Chile" 46 y les dedicó una arpillera elaborada con tierra posterior a su encuentro, Mira la lucha del afuerino. De acuerdo a Matta, la finalidad de reunirse con ellos era la de convencerlos para que conformaran un sindicato y defendieran sus derechos. Los afuerinos como lo consignó el presidente Salvador Allende en su

45 Declaración General del Congreso Cultural de La Habana, publicada en Cuadernos de Cultura, Buenos Aires, año XVIII, no89, mayo-junio, 1968

${ }^{46}$ Eduardo Carrasco, Matta conversaciones, Santiago: Cesoc, 1987 
discurso sobre la propiedad agraria en agosto de 1971, eran "chilenos sin tierra, viviendas, derechos de previsión, al margen de toda protección legal y en condiciones infrahumanas de existencia" ${ }^{4}$.

Alberto Pérez y Patricia Israel, América despierta.

Serigrafía, 1972. Colección Privada

En el plan de fortalecer la organización y erradicar la inferioridad social de los afuerinos, Pérez se dedicó a su alfabetización y al trabajo gráfico en la sección de comunicaciones del ICIRA junto a la artista Patricia Israel. De esta gestión colectivista, se desprende la serigrafía titulada La unidad campesina es el camino al poder Consejo comunal, donde retratan a un hombre vestido de poncho verde, descalzo y una herramienta similar al azadón para remover la tierra. Las serigrafías de estos años, estaban arraigadas en el socialismo y en la profundización de las reformas de Allende desde su vertiente más enérgica y revolucionaria. Mientras que en la serigrafía Por un Chile socialista (circa 1971) aglutinó a líderes que movilizaron el despertar de la clase obrera desde las filas socialistas como Luis Emilio Recabarren, Pedro Aguirre Cerda y el mismo Salvador Allende, la emblemática serigrafía América despierta de 1972 representó el reflorecimiento de la herencia hispánica, africana e indígena y la expresividad de integración real y abierta de Latinoamérica tal como se traduce en la exaltación simbólica y colorida de héroes, fauna y alimentos sobre el mapa que une la geografía caribeña con el subtrópico del Cono sur. Esta serigrafía tuvo la singular cualidad de contar con una complejísima manufactura de trece colores, dividida en dos pliegos y de representar por, sobre todo, la unión de Latinoamérica desde los polos culturales y políticos de Cuba y Chile. La serigrafía fue exhibida con el apoyo del Instituto de Arte Latinoamericano de la Universidad de Chile en la trigésima sexta Bienal de Venecia en junio de 1972, siendo seleccionada para la sección de diseño gráfico experimental.

La impronta gráfica, su concreta simbología socialista y su circulación nacional e internacional, tuvo, a pocos días del golpe de Estado de la Junta Militar, su revés más violento: la quema pública frente a las Torres San Borja de la serigrafía junto con los libros, entre otros, de Ariel Dorfman y Armand Mattelart, Para leer al Pato Donald. La destrucción de la serigrafía fue publicada a primera plana en el diario La Tercera, el día 21 de septiembre de 1973. En la imagen, se observaba a los militares destruyendo todo lo que era considerado "propaganda extremista".

La última lucha social y combativa a la que apelaba Pérez se convirtió de golpe en una barricada de fuego dando sepulcro a la agitación revolucionaria y a la muerte del sistema democrático socialista. En el momento de la destrucción violenta y visible de la serigrafía América despierta, subyacían invisiblemente el inicio de las desapariciones, torturas y muertes de estudiantes, obreros y campesinos, volcando el ambiente social y artístico en una oscura y silenciada comunicación, frente a las brutalidades de las fuerzas militares. Después del 11 de septiembre de 1973, "nada ocurría que no fuera miedo y desesperanza", le dirá Pérez en una entrevista a Claudia Zaldívar. "Llegó la barbarie, el deseo de atropellar el orden establecido, era una sensación de angustia. La gente moría todos los días y las obras no tenían importancia" 48 . Pérez fue exonerado de la Universidad de Chile y buscó integrarse en espacios de disidencia al régimen como la Galería Paulina Waugh, la Unión Nacional por la Cultura (UNAC) o el Centro Imagen, con saldos muchas veces, negativos. Las galerías fueron incendiadas, la censura prevaleció en los ámbitos culturales, las desapariciones y las muertes aumentaron reproduciendo un torbellino de traumas que no cesó nunca. Luego de cinco años de regimen, el hallazgo de las osamentas de quince cuerpos en los hornos de Lonquén fue la primera noticia que se publicó en la revista Hoy, donde se reconoció el rastro de hombres, en su mayoría jóvenes y campesinos

47 Salvador Allende, discurso sobre la propiedad agraria, 23 de agosto de 1971 . Acceso: https://www.marxists.org/espanol/allende/1971/agosto23.htm

${ }^{48}$ Entrevista de Claudia Zaldívar a Alberto Pérez, 6 de octubre, 1990. Archivo Museo de la Solidaridad Salvador Allende 
asesinados, víctimas de la masacre y de los ocultamientos la dictadura, y que despertó la conmoción pública local e internacional.

La última barricada de Pérez fue Bandera de Lonquén que ensambló en 1985 con retazos de maderas, trapos y arpilleras viejas. La Bandera guerrillera de 1964 que alentó el espíritu de lucha, se transformó veinte años después, en un emblema macabro de los campesinos muertos: despojos corporales de lo que quedó destrozado, perdido, derrotado, sin flamear, sin habla, sin esperanza.

Luego del silencio obligado de la dictadura y de un autoexilio en su casa de Farellones, Peréz se incorporó en 1981 como docente en la Universidad Central y Universidad Católica. A fines de la década de los noventa se reincopora a la Facultad de Artes de la Universidad de Chile, desencantado por la dirección democrática del país. Rebelde de los recuentos de una historia biográfica individual, muere al margen de todo homenaje, en julio de 1999.

\section{El revés y el derecho}

Este texto buscó reconocer el espesor material y mental de Alberto Pérez, un artista que, obstinado con la guerrilla interior y exterior, hizo cambios radicales e inminentes al acontecer de los tiempos convulsos y violentos de la decáda de 1960. Sin terminos medios, estuvo inmerso en la problemática social de su tiempo con su doble cara de dolor ante la muerte y la reivindicación de poder integrar la transformación liberadora de las colectividades culturales, artísticas, estudiantiles y campesinas. En el relato, se reconstruyó los tres momentos de los usos alegóricos de las barricadas y que, vistos en retrospectiva, se observan como una fuerza representativa de las reformulaciones creativas de Pérez. Apropiadas desde el combate de la calle, las barricadas traspasaron su mera contemplación estética para instalarse en el propio cuerpo y quehacer del artista. La barricada retrató a Pérez en su oposición a las imposiciones coloniales y desiguales para abrir paso a la participación y creación directa con el pueblo. La barrera invisible pero efectiva que se sostuvo en el Museo de Arte Contemporáneo y que puso freno a la despolitización y la intervención económica de capitales nacionales y norteamericanos, se encauzó hacia el norte de la solidaridad revolucionaria: latinoamerica orbitó en Argelia, en Vietnam, pero sobre todo en Cuba. La lucha guevarista ofreció una acción concreta de cómo recuperar la libertad y dignidad en el Cono sur. Destruir la propiedad individual era, en la utopía revolucionaria, crear un mundo común. Rebelde de las limitaciones artísticas, Pérez se integra a la instrucción para-militar y guerrillera de la red revolucionaria ELN. Esta última barricada, que abre y cierra el lapso de los avatares más agresivos y radicales de las convicciones de Pérez, se erije en una barricada de fuego y unión plena con la miseria de los afuerinos. El revés y el derecho de las barricadas fueron los propios contrastes de la trayectoria de Pérez. Estos episodios, que no han tenido cabida en los recuentos de la historia reciente del arte chileno, y que por muchos años han permanecido silenciados, rechazados y olvidados, requieren de una nueva barricada: resistir las tabulas rasas que han borrado los agentes de convicciones revolucionarias dentro de la historia.

\section{Bibliografía}

Badenes, Patricia, La estética de la barricada: Mayo del 68 y la creación artística, Castelló de la plana: Universidad Jaume I., 2006

Berríos, María, "Struggle as Culture: The Museum of Solidarity, 1971-73" en Journal Afterall 44, Autumn/Winter, 2017

Bianchi, Soledad Libro de Lectura(s), Poesía-poetas-poéticas, Santiago: Universidad de Santiago de Chile, 2014 
Galaz, Gaspar, Ivelic, Milan, Chile Arte Actual, Valparaíso: Ediciones Universitarias de Valparaíso, 1988

Cazanga Moncada, Osvaldo, Historia crítica de la educación pública en Chile, Rialstat Editores:

Santiago, 2017

Harmer, Tanya, Riquelme Segovia, Alfredo Eds., Chile y la Guerra Fría, Santiago: Ril Editores, 2014

Gimpel, Jean, Contra el arte y los artistas, o el nacimiento de una religión. Barcelona: Gedisa, 1979

Giunta, Andrea, Vanguardia, Internacionalismo y Politica. Arte argentino en los años sesenta, Buenos Aires: Siglo veintiuno editores, 2008

Gordon, Avery F., Letters from the utopian margins. The Hawthorn archive, New York: Fordham University Press, 2018

Longoni, Ana, Vanguradia y revolución. Arte e izquierdas en la Argentina de los sesenta-setenta, Buenos Aires: Ariel, 2014

Pérez, Alberto, La pintura cubana en la revolución, Revista Atenea, 1970

Concepción del arte y la visión del artista en Camus, Revista de Filosofía, No1-2 Vol XII, 1965

Macchiavello, Carla, Juaréz, Silvia, "Solidaridad, plástica, redes y revolución: una crónica

breve del surgimiento y oclusión del meridiano Chile-Cuba en el ámbito del arte latinoamericano" en

Redes intelectuales. Arte y politica en América Latina, María Clara Bernal, Comp., Bogotá: Ediciones

Uniandes, 2015

Matta, Roberto. Hacer la guerrilla interior, Congreso de la Habana, 68 o 69

Marcuse, Herbert, Un ensayo sobre la liberación, México: Editorial Joaquín Mortiz, 1969

Maruenda, Félix, Felix Maruenda. Sin miedo, Fundación Pablo Nerurda: Santiago, 2007

Miras, Pedro, Alberto Pérez en la Reforma universtaria. En Revista Electrónica de Arte, REA, 2007. Ver: http://arteuchile.uchile.cl/rea/. Acceso: 2017

Núnez, Guillermo, Retrato hablado: Una retrospectiva. Santiago: Museo de Arte Contemporáneo, Universidad de Chile, 1993

Rasmussen, Waldo, MoMA Archives Oral History, New York: MoMA, 1994, pp.175.https://www.moma.org/momaorg/shared/pdfs/docs/learn/archives/transcript rasmussen.pdf.

Acceso: 28/07/2017

Sociedad Amigos del Museo de Arte Contemporáneo de la Universidad de Chile, Santiago: Editorial Universitaria, 1966

Schubert, Karen, The Curators's Egg, The evolution of the museum concept from the French Revolution to the present day, London: Ridinghouse, 2000 